\title{
Nonisothermal models to determine the rheological constants of different Kuwaiti crude oils
}

\author{
Bader Albusairi* and Adam Al-Mulla \\ Department of Chemical Engineering, Kuwait University, P.O. Box 5969, Safat 13060, Kuwait \\ * Corresponding Author: bader.albusairi@ku.edu.kw
}

$\begin{array}{ll}\text { Submitted } & : 30 / 10 / 2020 \\ \text { Revised } & : 11 / 04 / 2021 \\ \text { Accepted } & : 19 / 04 / 2021\end{array}$

\begin{abstract}
The rheological characteristics of four Kuwaiti crude oil samples collected from four different collection points, namely, MG 23T, MG 29T, MG 34T, and MG 108T, were investigated. The investigations were conducted in the temperature range of 298-313 K using the Bingham, Ostwald-de Waele, Herschel-Bulkley, Casson, and modified Casson models. The experimental data of the shear stress were modeled as a function of the shear rate and temperature. Statistical estimations were used to determine the most accurate model and nonisothermal empirical relations. The Ostwald-de Waele and Herschel-Bulkley models yielded the most accurate predictions for MG 23T, MG 29T, MG 108T, and MG 34T, respectively. It is noted that all the crude oils follow shear thinning behavior. Arrhenius-Eyring equation has been used to estimate the activation energy and the preexponential factor of these crude oils at a shear rate of $10.3 \mathrm{~s}^{-1}$.
\end{abstract}

Keywords: Kuwaiti crude oil; Rheology; Shear stress; Ostwald-de waele model; Herschel-bulkley model.

NOMENCLATURE

\begin{tabular}{|c|c|}
\hline Abbreviations & Meaning \\
\hline MG 23T & \multirow{4}{*}{ Crude oil sample at different collection points } \\
\hline MG 29T & \\
\hline MG $108 \mathrm{~T}$ & \\
\hline MG 34T & \\
\hline$\tau$ & Shear stress $(\mathrm{Pa})$ \\
\hline$\tau_{B}$ & Yield stress $(\mathrm{Pa})$ \\
\hline
\end{tabular}




\begin{tabular}{|c|l|}
\hline$k_{B}$ & Consistency factor \\
\hline$\gamma$ & Shear rate $\mathrm{s}^{-1}$ \\
\hline$n_{O}$ & \multirow{2}{*}{ Flow index } \\
\hline $\mathrm{A} 1$ & \multirow{2}{*}{ Model constants } \\
\cline { 1 - 1 } $\mathrm{A} 2$ & \\
\cline { 1 - 1 } $\mathrm{B} 1$ & \\
\cline { 1 - 1 } $\mathrm{B} 2$ & \\
\cline { 1 - 1 } $\mathrm{C} 1$ & \\
\cline { 1 - 2 } $\mathrm{C} 2$ &
\end{tabular}

\section{INTRODUCTION}

Predicting the rheological properties of crude oil is a key task in drilling, oil production, and storage applications. For instance, rheological data are required to accurately simulate and design many equipment used in petroleum refineries (Ding et al., 2006). In particular, to design pipelines, set the pump capacity, and establish production facilities, the shear stress is a key characteristic that must be predicted accurately. When refineries operate, the temperature of the crude oil changes constantly, and because the shear stress varies with temperature, the variation should be considered in the parameter estimation for various applications.

Kuwait produces crude oil of varying compositions. Crude oil is a complex fluid containing varying amounts of hydrocarbon compounds ranging from low molecular weight hydrocarbons such as waxes to asphaltenes, which have an extremely high molecular weight. Owing to the variation in its composition, crude oil behaves as a non-Newtonian fluid. For instance, crude oil may exhibit solid-like characteristics owing to the changes in the wax crystal structure. The presence of gases and low and high molecular compounds considerably influences the viscoelastic characteristics of bulk crude oil (Darby., 1976). In particular, the low molecular weight compounds in the oil, such as gases, and low molecular hydrocarbon compounds, such as alkanes, alkenes, and alkynes, exhibit Newtonian behavior. In contrast, compounds with a large molecular weight, such as agglomerates of waxes and asphaltenes, exhibit nonNewtonian characteristics.

At a given temperature, the relationship between the shear stress and the shear rate, viscosity, molecular weight, and density of crude oil is normally nonlinear (Albusairi \& Al-Mulla 2017, Ariffin, Yahya, and Husin 2016, Ronningsen 2012, 1995, 1992). When paraffin waxes, solid paraffin, or complex aromatic molecules exist in crude oil, changes in the temperature affect the viscosity, and non-Newtonian characteristics appear. All crude oils contain a certain amount of paraffin waxes, which begin to undergo deposition at low temperatures, thereby exhibiting nonNewtonian behavior (Ding et al., 2006, Ronningsen 1992). Therefore, prediction models for any type of crude oil must take into account the temperature variation.

Many empirical models have been used to predict the shear stress of crude oil as a function of temperature (Alomair, Elsharkawy, \& Alkandari 2014, Anto et al., 2020, Kamel, Alomair, and Elsharkawy 2019, Mendes et al. 2015, Ronningsen 2012). These models use up to eight parameters for shear stress determination (Mendes et al., 
2015). A detailed review pertaining to the prediction of different parameters to determine the shear stress has been provided by Alomair, Elsharkawy, and Alkandari (2014). Moreover, the proposed correlations for nonisothermal conditions in these literatures are either complicated or have low accuracy.

Furthermore, different models have been used to establish the relationship of the shear stress and the shear rate, with or without the consideration of the temperature as a variable to predict different parameters for vegetable oils (Abramovi \& Klofutar 1998, Esteban et al., 2012, Stanciu 2013a, b), water/oil emulsions (Ariffin, Yahya, \& Husin 2016, Ronningsen 1995), activated sludge (Khalili-Garakani et al., 2011), oil-based muds (Fakoya \& Ahmed 2018), and drilling fluids (Anawe \& Folayan 2018).

In this study, a simple procedure to use different models for determining the consistency factor, yield stress, and flow index of the rheological data of different crude oils was presented for nonisothermal conditions. The change in the rheological characteristics of different crude oils at different temperatures was investigated. Based on the findings of earlier investigations related to different fluid types, certain simple rheological models were used to fit the isothermal rheological data for four Kuwaiti crude oils. The most accurate model was modified to account for the temperature variations occurring during the rheological characterizations of crude oil. The modeling procedure was successful in obtaining a low level of error $(\sim 3.6 \%)$ for the predicted data.

\section{METHODOLOGY}

\section{Experimental Work}

The rheological characterization was performed using a Bohlin-Gemini 200, UK, instrument by using a CP 180cylinder Peltier to measure the flow properties of the liquids. The measurements were conducted at temperatures ranging from 298 to $313 \mathrm{~K}$ with $5 \mathrm{~K}$ increment, controlled using a Julabo F 25 water bath. An inbuilt electronic encoder in the rheometer was used to estimate the rheological properties of the samples for an applied stress of 106 impulses per rotation.

The impulse helps in determining the information related to the applied stress, stress rate, or yield occurring in a sample. A constant gap of $0.15 \mathrm{~mm}$ at a cone angle of $4^{\circ}$ was maintained. All the experiments were repeated three times to ensure the reproducibility of the results.

\section{Mathematical Modelling}

Several models have been proposed to estimate the flow properties of materials such as crude oils and polymer melt solutions (Barnes, Hutton, and Walters 1989, Darby 1976, Astarita, Marrucci, \& Joseph 1975, Ronningsen 2012, Albusairi and Al-Mulla 2017, Ariffin, Yahya, and Husin 2016, Middleman 1977, Bird and Hassager 1987). In general, an equation expressing the relation between the shear stress and shear rate includes two to five parameters. In this study, four of the most widely used models, namely, the Bingham (B), Ostwald-de Waele (O), HerschelBulkley (HB), and Casson (C) models, expressed in equations (1)-(4), respectively, were used to estimate the rheological constants. Moreover, a modified version of the $\mathrm{C}$ model was introduced, as given in equation (5).

$$
\tau=\tau_{B}+k_{B} \gamma
$$




$$
\begin{aligned}
& \tau=k_{O} \gamma^{n_{O}} \\
& \tau=\tau_{H B}+k_{H B} \gamma^{n_{H B}} \\
& \tau=\left(\tau_{C}^{0.5}+\left(k_{C} \gamma\right)^{0.5}\right)^{2} \\
& \tau=\left(\tau_{M C}^{0.5}+k_{M C}^{0.5} \gamma^{\left(\frac{n_{M C}}{2}\right)}\right)^{2}
\end{aligned}
$$

In these equations, the two variables $\tau$ and $\gamma$ correspond to the shear stress (in Pa) and shear rate (in $\mathrm{s}^{-1}$ ), respectively. $\tau_{i}, n_{i}$, and $k_{i}$ in equations (1)-(5) denote the model parameters, specifically, the yield stress (in Pa), flow or behavior index (dimensionless), and consistency factor (in Pa. $\mathrm{s}^{\mathrm{n}}$ ) for model $i=\mathrm{B}, \mathrm{O}, \mathrm{HB}, \mathrm{C}$, or MC. The yield stress is the stress required to initiate the flow of a fluid. The flow index is an indication of the non-Newtonian behavior of the fluid flow. Specifically, if $n_{i}=1, n_{i}>1$, or $n_{i}<1$, the fluid is a Newtonian fluid, shear-thickening fluid, or shear-thinning fluid, respectively.

The dependency of the shear stress on temperature $(\mathrm{K})$ was incorporated into the model parameters as expressed in equations (6)-(8), where $\mathrm{A} 1, \mathrm{~A} 2, \mathrm{~B} 1, \mathrm{~B} 2, \mathrm{C} 1$, and $\mathrm{C} 2$ represent the model constants. These parameters were determined numerically by fitting the experimental data.

$$
\begin{aligned}
& k_{i}=A 1 \exp \left[\frac{A 2}{T}\right] \\
& \tau_{i}=B 1+B 2 T^{-1} \\
& n_{i}=C 1+C 2 T
\end{aligned}
$$

To validate the models and their parameter settings, a $95 \%$ parameter confidence interval was used, which is a statistical parameter used to measure the variation in a parameter that results in a change of less than $5 \%$ in the dependent variable. Moreover, if the possible parameter value including a zero value, i.e., the interval value, was larger than the value of the parameter itself, the specific parameter was omitted. This aspect has been explained in depth by Cutlip \& Shacham (2008). Different statistical were used to determine the optimal model, specifically, the model with the R-squared value $\left(R^{2}\right)$ close to unity and the one with least variance $(\sigma)$.

\section{RESULTS AND DISCUSSION}

\section{Crude Oil Analysis}

Albusairi and Al-Mulla (2017) have used four different types of crude oils from four different wells, which were more than $10 \mathrm{Km}$ apart. They have analyzed the four different crude oils for their sulfur, refractive index, and density at $298 \mathrm{~K}$. These four crude oils have been used in this work to develop the mathematical model for the shear stress as function of shear rate and temperature. 


\section{Shear Stress Data}

Crude oils can be classified as either Newtonian or non-Newtonian depending on their viscosity, which is related to the chemical nature of the crude oil. From Figure 1, which is a plot of the shear stress versus the shear rate, a nonlinear trend can be noted at high shear rates, which implies the non-Newtonian nature of the oil. The deviation from linearity decreases with an increase in the temperature, owing to the melting of the high molecular weight compounds or waxes present in the crude oil.

Moreover, all the crude oil samples except those of MG 34T exhibit an intercept value close to the origin, which indicates the presence of an extremely low initial yield stress. In this regard, the use of models involving the initial yield stress may not be feasible. The apparent viscosity (slope of the shear stress vs. shear rate) of all the crude oils decreases with an increase in the shear rate, which indicates that all the crude oils are shear thinning fluids. Accordingly, the flow index $(n)$ is expected to be less than one for all the samples.

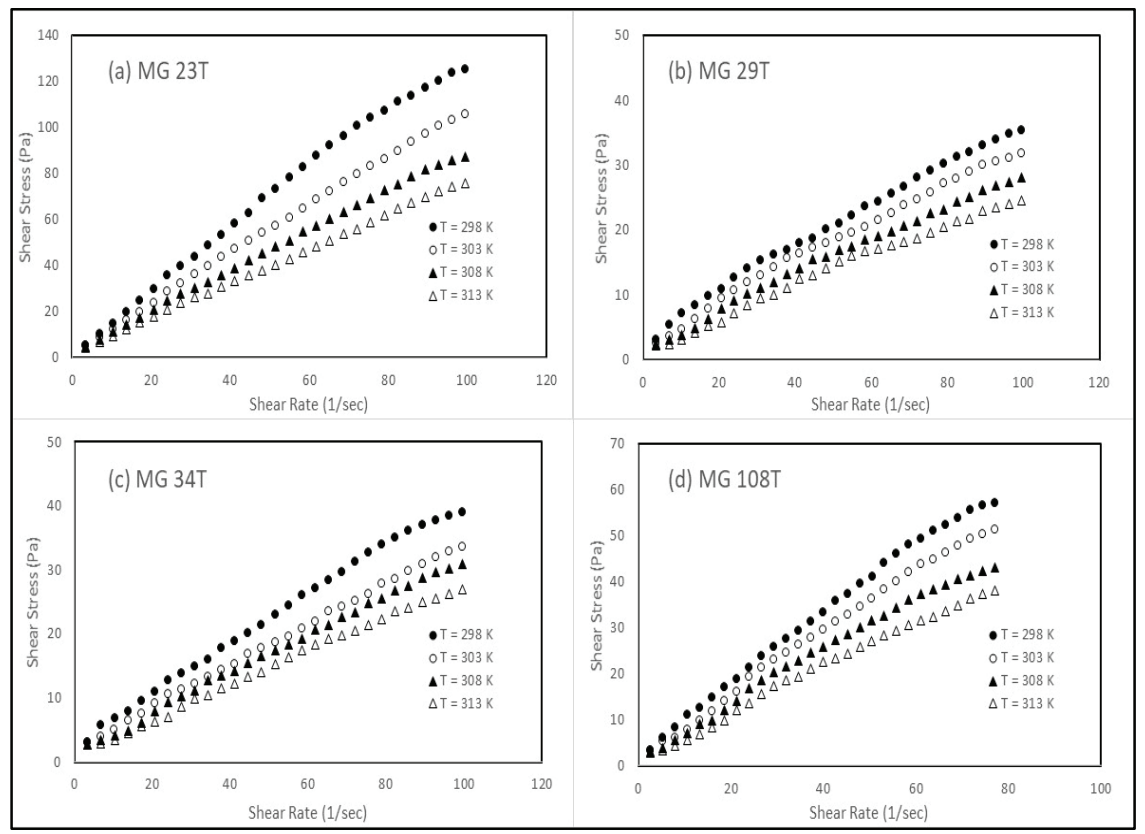

Figure 1. Experimental data of the four crude oil samples each at the four elected temperatures.

(a) MG 23T, (b) MG 29T, (c) MG 34T, and (d) MG 108T. 
Table 1. Regression parameters of the five proposed models for four crude oils.

\begin{tabular}{|c|c|c|c|c|c|c|c|c|c|c|c|c|c|c|}
\hline \multirow{2}{*}{\multicolumn{3}{|c|}{\begin{tabular}{|c|} 
Model \\
Parameter \\
\end{tabular}}} & \multicolumn{2}{|c|}{ B } & \multicolumn{2}{|c|}{$\mathrm{O}$} & \multicolumn{3}{|c|}{$\mathrm{HB}$} & \multicolumn{2}{|c|}{ C } & \multicolumn{3}{|c|}{ MC } \\
\hline & & & $\tau_{B}$ & $k_{B}$ & $k_{0}$ & $\mathrm{n}_{\mathrm{o}}$ & $\tau_{H B}$ & $k_{H B}$ & $n_{H B}$ & $\tau_{c}$ & $k_{c}$ & $\tau_{M C}$ & $k_{M C}$ & $\mathrm{n}_{\mathrm{MC}}$ \\
\hline \multirow{16}{*}{ 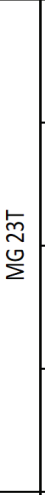 } & \multirow{4}{*}{ 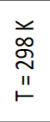 } & value & 4.351 & 1.291 & 2.096 & 0.898 & -5.625 & 3.056 & 0.824 & 0.542 & 1.1587 & $7 E-20$ & 2.0405 & 0.9044 \\
\hline & & 95\% Conf. & 2.272 & 0.039 & 0.2524 & 0.0282 & 1.646 & 0.1872 & 0.0125 & 0.3964 & 0.0712 & $8 \mathrm{E}-15$ & $7 \mathrm{E}-06$ & $4 E-07$ \\
\hline & & $R^{2}$ & \multicolumn{2}{|c|}{0.9943} & 0.9 & 970 & & 0.9978 & & 0.9 & 958 & & 0.9970 & \\
\hline & & $\sigma^{2}$ & 8.4 & 359 & 4.4 & 677 & & 3.4040 & & $6.2 C$ & 043 & & 4.6769 & \\
\hline & & value & 2.675 & 1.061 & 1.5459 & 0.9192 & -0.262 & 1.499 & 0.929 & 0.2152 & 0.9876 & $1 \mathrm{E}-22$ & 1.459 & 0.934 \\
\hline & \% & 95\% Conf. & 0.6994 & 0.0119 & 0.097 & 0.0171 & 0.451 & 0.035 & 0.0048 & 0.0748 & 0.0196 & $1 \mathrm{E}-16$ & $2 \mathrm{E}-06$ & $2 \mathrm{E}-07$ \\
\hline & $m$ & $R^{2}$ & 0.9 & 992 & 0.9 & 978 & & 0.9997 & & 0.9 & 996 & & 0.9997 & \\
\hline & & $\sigma^{2}$ & 0.7 & 996 & 0.5 & 289 & & 0.2953 & & 0.43 & 365 & & 0.2987 & \\
\hline & & value & .875 & 0.8774 & 1.293 & 0.9205 & 0.8235 & 1.179 & 0.939 & 0.2732 & 0.8041 & 0.0714 & 1.026 & 0.959 \\
\hline & $\frac{10}{\circ}$ & 95\% Conf. & 0.602 & 0.0102 & 0.0669 & 0.0121 & 1.106 & 0.1606 & 0.028 & 0.0841 & 0.0177 & 0.226 & 0.392 & 0.0642 \\
\hline & $m_{11}$ & $\mathrm{R}^{2}$ & 0.99 & 991 & 0.9 & 995 & & 0.9995 & & 0.99 & 994 & & 0.9995 & \\
\hline & & $\sigma^{2}$ & 0.5 & 924 & 0.3 & 675 & & 0.3505 & & 0.3 & 701 & & 0.3601 & \\
\hline & & value & 2.203 & 0.3813 & 1.037 & 0.935 & 1.7677 & 0.813 & 0.984 & 0.1714 & 0.7003 & 0.5326 & 0.4926 & 1.061 \\
\hline & $\stackrel{m}{\rightarrow}$ & 95\% Conf. & 0.7528 & 0.0065 & 0.064 & 0.0144 & 0.5802 & 0.0637 & 0.0162 & 0.0593 & 0.0145 & 0.4308 & 0.1665 & 0.0586 \\
\hline & m & $R^{2}$ & 0.95 & 996 & 0.9 & 993 & & 0.9995 & & 0.9 & 995 & & 0.9996 & \\
\hline & & $\sigma^{2}$ & 0.2 & 376 & 0.3 & 720 & & 0.2342 & & 0.2 & 469 & & 0.2187 & \\
\hline & & value & 4.217 & 0.3262 & 1.158 & 0.7442 & 1.474 & 0.8222 & 0.8111 & 1.207 & 0.2419 & 0.6193 & 0.413 & 0.909 \\
\hline & ळ & 95\% Conf. & 0.5342 & 0.0091 & 0.0849 & 0.0173 & 0.7948 & 0.1706 & 0.0416 & 0.1443 & 0.0081 & 0.5224 & 0.2128 & 0.0859 \\
\hline & $\pi$ & $\mathrm{R}^{2}$ & 0.9 & 951 & 0.9 & 981 & & 0.9987 & & $0.9 \mathrm{~s}$ & 986 & & 0.9988 & \\
\hline & & $\sigma^{2}$ & 0.4 & 664 & 0.1 & 761 & & 0.1232 & & 0.1 & 282 & & 0.0859 & \\
\hline & × & value & 2.949 & 0.3032 & 0.8616 & 0.7871 & -0.113 & 0.8864 & 0.7815 & 0.7166 & 0.2379 & $5 E-22$ & 0.8606 & 0.7873 \\
\hline & ஜ & $95 \%$ Conf. & 0.5852 & 0.0099 & 0.0658 & 0.018 & 0.9107 & 0.2132 & 0.048 & 0.1648 & 0.0118 & $3 E-16$ & $2 \mathrm{E}-06$ & $5 E-07$ \\
\hline & m & $\mathrm{R}^{2}$ & 0.95 & 932 & 0.9 & 983 & & 0.9983 & & 0.95 & 971 & & 0.9983 & \\
\hline হ్ & & $\sigma^{2}$ & 0.5 & 597 & 0.1 & 412 & & 0.1463 & & 0.2 & 382 & & 0.1466 & \\
\hline$\stackrel{0}{\Sigma}$ & & value & 2.241 & 0.2695 & 0.6839 & 0.8093 & -0.405 & 0.7688 & 0.7864 & 0.4925 & 0.2174 & $5 E-22$ & 0.6792 & 0.8109 \\
\hline & \% & $95 \%$ Conf. & .5188 & 0.0088 & 0.0565 & 0.0194 & 0.2259 & 0.0138 & 0.0039 & 0.1408 & 0.0116 & $2 \mathrm{E}-16$ & $2 \mathrm{E}-06$ & $6 \mathrm{E}-07$ \\
\hline & III & $\mathrm{R}^{2}$ & 0.9 & 932 & 0.9 & 981 & & 0.9982 & & 0.9 & 967 & & 0.9981 & \\
\hline & & $\sigma^{2}$ & 0.4 & 398 & 0.1 & 210 & & 0.1206 & & 0.2 & 149 & & 0.1258 & \\
\hline & Y & value & 1.584 & 0.2419 & 0.5307 & 0.8379 & -0.726 & 0.6741 & 0.7911 & 0.2997 & 0.2022 & $7 E-21$ & 0.5216 & 0.842 \\
\hline & $\vec{m}$ & $95 \%$ Cor & 5279 & 0.0089 & 0.0602 & 0.0266 & 0.4097 & 0.0524 & 0.0158 & 1422 & 0.0144 & $1 \mathrm{E}-15$ & $2 \mathrm{E}-06$ & $8 \mathrm{E}-07$ \\
\hline & $m$ & $\mathrm{R}^{2}$ & 0.95 & 910 & 0.9 & 960 & & 0.9963 & & 0.95 & 942 & & 0.9960 & \\
\hline & $r$ & $\sigma^{2}$ & 0.4 & 554 & 0.2 & 105 & & 0.2006 & & 0.36 & 044 & & 0.2192 & \\
\hline & $\underline{x}$ & value & 3.197 & 0.3803 & 0.9217 & 0.8203 & 1.303 & 62 & \begin{tabular}{|l|}
0.8787 \\
\end{tabular} & 0.6601 & 0.31 & 0.3553 & 0.4326 & 0.9433 \\
\hline & $\infty$ & $95 \%$ Conf. & .5341 & 0.0091 & 0.0894 & 0.0228 & 0.4517 & 0.0421 & 0.0126 & 0.1592 & 0.0135 & 0.0568 & 0.0102 & 0.0051 \\
\hline & $\sim$ & $\mathrm{R}^{2}$ & 0.95 & 964 & 0.9 & 974 & & 0.9979 & & 0.9 & 978 & & 0.9978 & \\
\hline & & $\sigma^{2}$ & 0.46 & 662 & 0.3 & 270 & & 0.2773 & & $0.2 \varepsilon$ & 889 & & 0.2899 & \\
\hline & & value & 356 & 0.3174 & 695 & 0.8411 & 1.258 & 0.4855 & 0.9 & .4333 & 0.2651 & 0.4457 & 07 & 1.003 \\
\hline & $\bar{m}$ & 95\% Conf. & 0.3962 & 0.0067 & 0.0723 & 0.0244 & 0.3694 & 0.0304 & 0.0129 & 0.1174 & 0.0113 & 0.1963 & 0.0586 & 0.0389 \\
\hline & m & $\mathrm{R}^{2}$ & 0.95 & 971 & 0.9 & 972 & & 0.9979 & & 0.95 & 978 & & 0.9978 & \\
\hline 点 & & $\sigma^{2}$ & 0.2 & 566 & 0.2 & 468 & & 0.1940 & & $0.1 \mathrm{~s}$ & 921 & & 0.1995 & \\
\hline$\stackrel{10}{5}$ & & value & 683 & 0.3025 & 5602 & 0.8744 & .7032 & 0.4512 & 0 & 2467 & 0.263 & 1233 & 58 & .959 \\
\hline & $\infty$ & 95\% Conf. & .3199 & 0.0054 & 0.0468 & 0.0196 & 0.2104 & 0.0076 & 0.0037 & 0.0744 & 0.0095 & 0.0885 & 0.0600 & 0.0304 \\
\hline & ల్ల & $R^{2}$ & 0.9 & 979 & 0.9 & 984 & & 0.9986 & & 0.9 & 985 & & 0.9985 & \\
\hline & & $\sigma^{2}$ & 0.16 & 673 & 0.1 & 303 & & 0.1144 & & 0.1 & 208 & & 0.1223 & \\
\hline & & value & 284 & 0.2663 & 4566 & 0.89 & 5595 & 0.3742 & 0 & .1641 & 0.2 & 0.498 & 24 & 946 \\
\hline & $\bar{m}$ & 95\% Conf. & 0.3177 & 0.0054 & 0.0469 & 0.024 & 0.3071 & 0.0237 & 0.0131 & 0.0719 & 0.0106 & 0.0188 & 0.0076 & 0.0051 \\
\hline & $m$ & $R^{2}$ & 0.99 & 974 & 0.9 & 977 & & 0.9979 & & 0.9 & 977 & & 0.9978 & \\
\hline & & $\sigma^{2}$ & 0.1 & 649 & 0.1 & 456 & & 0.1371 & & 0.1 & 451 & & 0.1468 & \\
\hline & & value & 288 & 0.8622 & 1.41 & 0.8606 & 0.469 & 1.507 & 0.8567 & .5386 & 0.636 & $5 E-22$ & 1.4022 & 0.8619 \\
\hline & ळ & 95\% Conf. & 0.8622 & 0.0189 & $3 \mathrm{E}-06$ & $6 \mathrm{E}-07$ & 0.6185 & 0.0796 & 0.0114 & 0.1912 & 0.0291 & $3 \mathrm{E}-16$ & $3 E-06$ & $6 \mathrm{E}-07$ \\
\hline & $\sim$ & $\mathrm{R}^{2}$ & 0.95 & 959 & 0.9 & 984 & & 0.9984 & & 0.9 & 976 & & 0.9984 & \\
\hline & & $\sigma^{2}$ & 1.2 & 150 & 0.4 & 778 & & 879.000 & & 0.7 & 032 & & 0.4966 & \\
\hline & & value & 2.186 & 0.6689 & 1.12 & 0.887 & -1.186 & 1.355 & 0.8473 & 0.2944 & 0.592 & $1 \mathrm{E}-20$ & 1.103 & 0.8906 \\
\hline & $\bar{\delta}$ & 95\% Conf. & 0.8227 & 0.018 & 0.1083 & 0.0241 & 0.6335 & 0.0814 & 0.013 & 0.0273 & 0.0054 & $2 \mathrm{E}-15$ & $3 E-06$ & $7 E-07$ \\
\hline & $m$ & $\mathrm{R}^{2}$ & 0.95 & 954 & 0.9 & 977 & & 0.9979 & & 0.95 & 968 & & 0.9977 & \\
\hline 东 & & $\sigma^{2}$ & 1.1 & 060 & 0.5 & 472 & & 0.5124 & & 0.7 & 682 & & 0.5703 & \\
\hline (ำ & & value & 2.325 & 0.5636 & 1.076 & 0.8581 & -1.856 & 1.492 & 0.7907 & 0.3908 & 0.4829 & $3 E-21$ & 1.052 & 0.8636 \\
\hline & $\infty$ & 95\% Conf. & 0.9123 & 0.02 & 0.1264 & 0.0293 & 0.6672 & 0.1035 & 0.0148 & 0.0952 & 0.0148 & $1 \mathrm{E}-15$ & $4 \mathrm{E}-06$ & $9 E-07$ \\
\hline & $m$ & $\mathrm{R}^{2}$ & 0.95 & 920 & 0.9 & 964 & & 0.9971 & & 0.99 & 946 & & 0.9963 & \\
\hline & & $\sigma^{2}$ & 1.3 & 600 & 0.6 & 186 & & 0.5212 & & 0.9 & 234 & & 0.6460 & \\
\hline & & value & 1.585 & 0.736 & 0.8322 & 0.8844 & -1.299 & 1.098 & 0.827 & 0.2186 & 0.4351 & $1 \mathrm{E}-20$ & 0.8145 & 0.8898 \\
\hline & 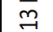 & 95\% Conf. & 0.4925 & 0.0161 & 0.0942 & 0.0282 & 0.6103 & 0.0839 & 0.0164 & 0.1502 & 0.0296 & $2 \mathrm{E}-15$ & $3 E-06$ & $9 E-07$ \\
\hline & m & $\mathrm{R}^{2}$ & 0.9 & 932 & 0.9 & 961 & & 0.9966 & & 0.9 & 948 & & 0.9961 & \\
\hline & & $\sigma^{2}$ & 0.8 & 855 & 0.5 & 078 & & 0.4614 & & 0.6 & 714 & & 0.5298 & \\
\hline
\end{tabular}


Furthermore, the shear stress varied with the shear rate. In this study, the crude oils were tested using five simple models relating the shear stress with shear rate, as described in equations (1)-(5). The regression parameters for the five models are listed in Table 1.

The regression results for all the crude oils were compared in terms of the $R^{2}$, variance, $95 \%$ confidence, and/or physical interpretation, to determine the optimal model. Figure 1 indicates that temperature influences the stress values. Moreover, with an increase in the temperature, the flow properties are improved owing to the minimal drag occurring because of the low chance of formation of the agglomerates containing waxes, asphaltenes, or other resins. Nearly all the $n_{i}$ values are less than 1 , which confirms that the Kuwaiti crude oil samples are shear thinning fluids.

\section{Isothermal Data Model Regression and Selection}

According to Table 1, the B model corresponded to the lowest and highest $\mathrm{R}^{2}$ and variance values, respectively, except in the case of MG $23 \mathrm{~T}$ at $313 \mathrm{~K}$. This aspect was a statistical indication of the poor representation of the experimental data, as this model considers that a linear relationship exists between the shear stress and shear rate. Consequently, this model could not accurately represent the experimental data for the four crude oil samples, and it was not used in further analyses.

The yield stress values for MG 23T, MG 29T, and MG 108T obtained using the HB and MC models were negative, and the $95 \%$ confidence interval values were higher than the corresponding parameters, except in the cases of MG $23 \mathrm{~T}$ at $313 \mathrm{~K}$ and MG $29 \mathrm{~T}$ at $298 \mathrm{~K}$. The negative values of the yield stress were physically unacceptable, because they indicated that the fluid started flowing by itself. Because the $95 \%$ confidence interval values were considerably higher than the yield stress values, the yield stress could be neglected. Thus, both the HB and MC models reduced to the $\mathrm{O}$ model and were not considered in the further analyses of MG 23T, MG 29T, and MG 108T. The remaining models ( $\mathrm{O}$ and $\mathrm{C}$ models) exhibited comparable variance and $R^{2}$ values; however, on average, the values for the $\mathrm{O}$ model were slightly lower for variance and higher for $R^{2}$. This is due to the extremely low yield stress for MG 23T, MG29T, and MG108T, as shown in Figure 1. Therefore, the C and O models were used to take into account the effect of the temperature on the properties of MG 23T, MG 29T, and MG 108T.

Nevertheless, the HB and MC models were used to examine the sample MG 34T, because of their low average variance, high average $R^{2}$, and high degree of freedom (more parameters). Owing to the yield stress noted in Figure 1 , the $\mathrm{O}$ model cannot be used for the parameter estimation of this sample.

\section{Selection of Model for Analysis of Non-Isothermal Data}

The relation between the various model parameters and the temperature was examined. Equations (6)-(8) were used to determine the consistency factor, yield stress, and flow index for all the models, respectively. This selection was made on the basis of the variation trend of the different parameters listed in Error! Reference source not found.. A similar approach has been adopted in existing studies (Alomair, Elsharkawy, and Alkandari 2014, Anawe and Folayan 2018, Anto et al., 2020, Esteban et al. 2012, Stanciu 2013a, Fakoya \& Ahmed 2018). 


\begin{tabular}{|c|c|c|c|c|c|c|c|c|c|c|c|c|c|}
\hline \multirow{3}{*}{\multicolumn{2}{|c|}{$\begin{array}{c}\text { Model } \\
\text { Parameters }\end{array}$}} & \multicolumn{6}{|c|}{ Ostwald-De-Waelle (0) model } & \multicolumn{6}{|c|}{ Casson (C) Model } \\
\hline & & \multicolumn{2}{|c|}{$\mathrm{k}_{0}$} & \multicolumn{2}{|c|}{$\mathrm{n}_{0}$} & & & \multicolumn{2}{|c|}{$\mathrm{k}_{\mathrm{c}}$} & \multicolumn{2}{|c|}{$\tau_{c}$} & & \\
\hline & & A1 & $\mathrm{A} 2$ & $\mathrm{C} 1$ & $\mathrm{C} 2$ & & & $\mathrm{~A} 1$ & $\mathrm{~A} 2$ & B1 & B2 & & \\
\hline \multirow{4}{*}{ 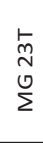 } & value & $3.49 \mathrm{E}-07$ & 4648.1 & 0 & $3.02 \mathrm{E}-03$ & & & $2.24 \mathrm{E}-03$ & 1846.4 & 0.561 & 0 & & \\
\hline & 95\% Conf. & $8.13 \mathrm{E}-08$ & 66.1 & 0 & $3.49 \mathrm{E}-05$ & & & $3.46 \mathrm{E}-04$ & 45.2 & 0.088 & 0 & & \\
\hline & $R^{2}$ & \multicolumn{4}{|c|}{0.99835} & & & \multicolumn{4}{|c|}{0.99780} & & \\
\hline & $\sigma^{2}$ & \multicolumn{4}{|c|}{1.65378} & & & \multicolumn{4}{|c|}{2.20619} & & \\
\hline \multirow{4}{*}{$\begin{array}{l}\text { D } \\
\text { N } \\
\text { D } \\
\Sigma\end{array}$} & value & $2.73 \mathrm{E}-07$ & 4541.6 & -0.885 & $5.49 \mathrm{E}-03$ & & & $7.96 \mathrm{E}-02$ & 545.1 & -10.609 & 3485.204 & & \\
\hline & $95 \%$ Conf. & $6.32 \mathrm{E}-08$ & 68.9 & 0.054 & $1.76 \mathrm{E}-04$ & & & $1.18 \mathrm{E}-02$ & 44.9 & 0.564 & 172.3754 & & \\
\hline & $R^{2}$ & \multicolumn{4}{|c|}{0.99753} & & & \multicolumn{4}{|c|}{0.99712} & & \\
\hline & $\sigma^{2}$ & \multicolumn{4}{|c|}{0.19233} & & & \multicolumn{4}{|c|}{0.22480} & & \\
\hline \multirow{4}{*}{ 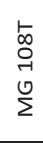 } & value & $1.78 \mathrm{E}-04$ & 2667.1 & 0.871 & 0 & & & $1.72 \mathrm{E}-02$ & 1145.6 & -5.325 & 1806.498 & & \\
\hline & $95 \%$ Conf. & 4.84E-05 & 81.1 & 0.013 & 0 & & & $2.89 \mathrm{E}-03$ & 50.7 & 0.874 & 268.7799 & & \\
\hline & $R^{2}$ & \multicolumn{4}{|c|}{0.99709} & & & \multicolumn{4}{|c|}{0.99622} & & \\
\hline & $\sigma^{2}$ & \multicolumn{4}{|c|}{0.63679} & & & \multicolumn{4}{|c|}{0.83454} & & \\
\hline \multicolumn{2}{|c|}{ Model } & \multicolumn{6}{|c|}{ HB Model } & \multicolumn{6}{|c|}{ MC Model } \\
\hline \multirow{2}{*}{\multicolumn{2}{|c|}{ Parameters }} & \multicolumn{2}{|c|}{$k_{i}$} & \multicolumn{2}{|c|}{$\tau_{i}$} & \multicolumn{2}{|c|}{$n_{i}$} & \multicolumn{2}{|c|}{$k_{i}$} & \multicolumn{2}{|c|}{$\tau_{i}$} & & \\
\hline & & $\mathrm{A} 1$ & $\mathrm{~A} 2$ & B1 & B2 & $\mathrm{C} 1$ & $\mathrm{C} 2$ & $\mathrm{~A} 1$ & $\mathrm{~A} 2$ & B1 & B2 & $\mathrm{C} 1$ & $\mathrm{C} 2$ \\
\hline & value & $3.51 \mathrm{E}-06$ & 3612.5 & -10.35 & 3464.7 & 0 & $2.99 \mathrm{E}-03$ & $1.29 \mathrm{E}-04$ & 2398.4 & -2.1011 & 710.57 & 0.9625 & 0 \\
\hline F & 95\% Conf. & $1.26 \mathrm{E}-06$ & 91.6 & 6.27 & 1969.9 & 0 & $9.70 \mathrm{E}-05$ & $7.00 \mathrm{E}-06$ & 15.7 & 0.0946 & 29.99 & 0.0105 & 0 \\
\hline$\sum_{\Sigma}^{0}$ & $R^{2}$ & & & & & & & & & 0.99 & 54616 & & \\
\hline & $\sigma^{2}$ & & & & 863 & & & & & 0.44 & 1275 & & \\
\hline
\end{tabular}

Table 2. Regression parameters of MG 23T, MG 29T, and MG $108 \mathrm{~T}$ including the temperature as variable.

The regression analysis for MG 23T, MG 29T, and MG 108T was performed using the O and C models by using the nonlinear regression tool in the Polymath ${ }^{\circledR}$ software, and the obtained statistical parameters are listed in Table 2 . The $R^{2}$ value and variance for the $\mathrm{O}$ model were relatively high and low, respectively. The $95 \%$ confidence interval values for all the parameters were in the acceptable range. These statistical findings indicate that the $\mathrm{O}$ model can better represent the shear stress data of the three crude oil samples as a function of the shear rate and temperature, compared to the representation of the $\mathrm{C}$ model. This conclusion is in agreement with the experimental data, in which a negligible yield stress for MG 23T, MG 29T, and MG 108T was observed, as shown in Figure 1, although the C model incurred a yield stress.

To obtain the nonisothermal parameters (Table 2) for MG 34T, the regression analysis was performed using the HB and MC models. The $R^{2}$ value and variance for the HB model were relatively high and considerably low, respectively. The $95 \%$ confidence interval values for all the parameters were in the acceptable range. Thus, the HB model could better represent the shear stress of the MG 34T sample as a function of the shear rate and temperature, compared to the representation of the MC model. Moreover, the yield stress obtained using the HB model was similar to the experimental data shown in Figure 1.

Figure 2 shows the parity chart for the four crude oil samples; the O model was used for MG 23T, MG 29T, and MG 108T, and the HB model was used for MG 34T. At low shear stress values, the parameters were in agreement; however, as the shear stress increased, the values notably deviated from the equality line. If the deviation of the shear stress is considered within the absolute value of the data, a satisfactory agreement can be considered. The average error for all the predicted data was approximately 3.6\%. Accordingly, the predicted data were considered to be in excellent agreement with the experimental data. 


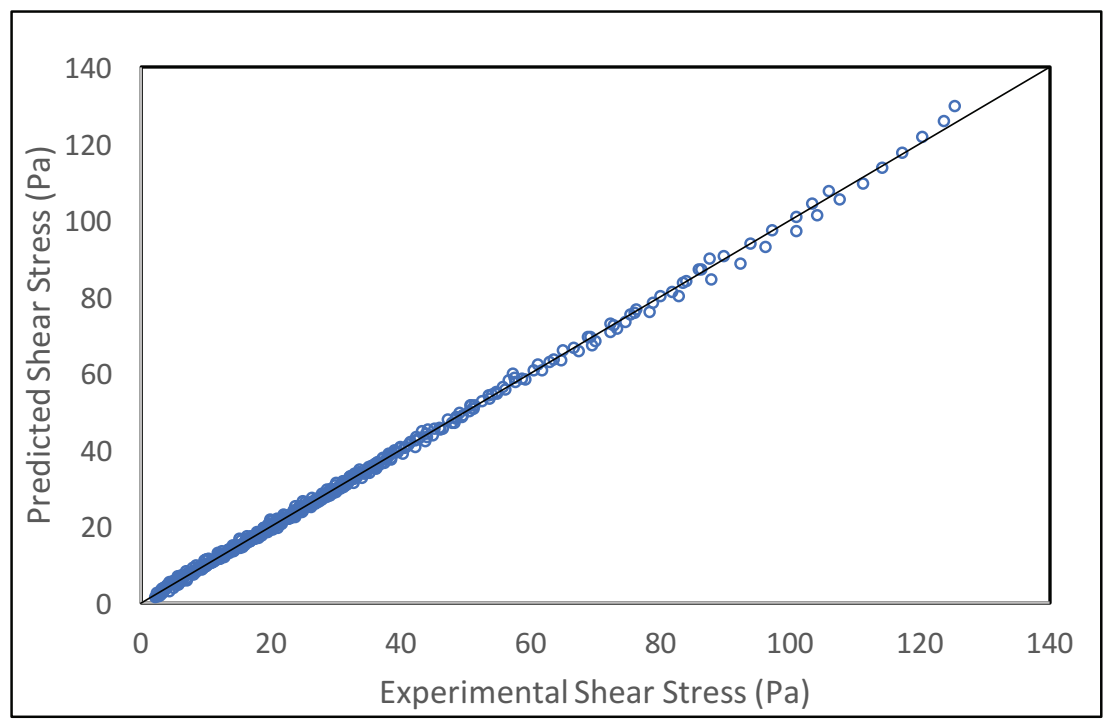

Figure 2. Parity chart for all four crude oil samples.

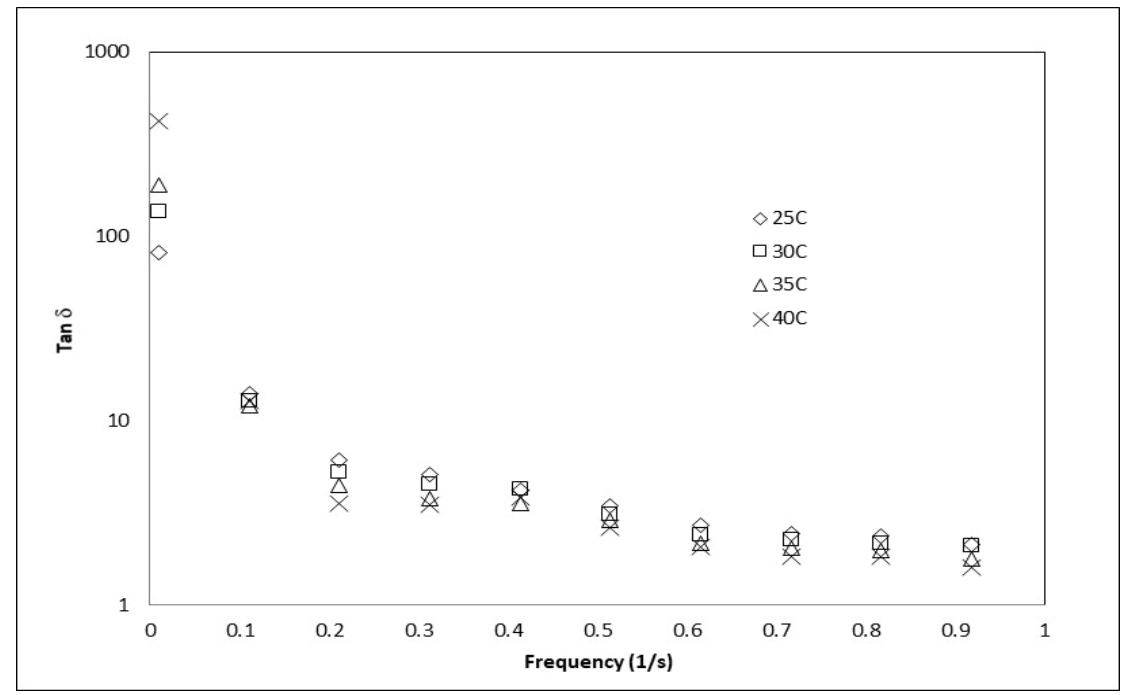

Figure 3. Tan $\delta$ Vs Frequency for MG 23T crude oil at different temperatures.

Tan $\delta$ is a ratio of loss modulus to storage modulus and represents the mechanism in which a material absorbs and dissipates energy. Tan $\delta$ versus frequency curves for a typical crude oil sample (MG 23T) at different temperatures are shown in

Figure 3. An important finding here is that the $\tan \delta$ values at the lowest frequency of $0.01 \mathrm{~s}^{-1}$ for the temperatures from $298(25), 303(30), 308(35)$ and $313(40) \mathrm{K}\left({ }^{\circ} \mathrm{C}\right)$ were found to be 81.4, 137, 189 and 418.9; respectively. Thus, as the temperature increases, the viscous modulus will be predominant in the oil samples. It is also noted that as the frequency increases, the $\tan \delta$ values decrease, indicating that the elastic nature in the molecules becomes dominant. 


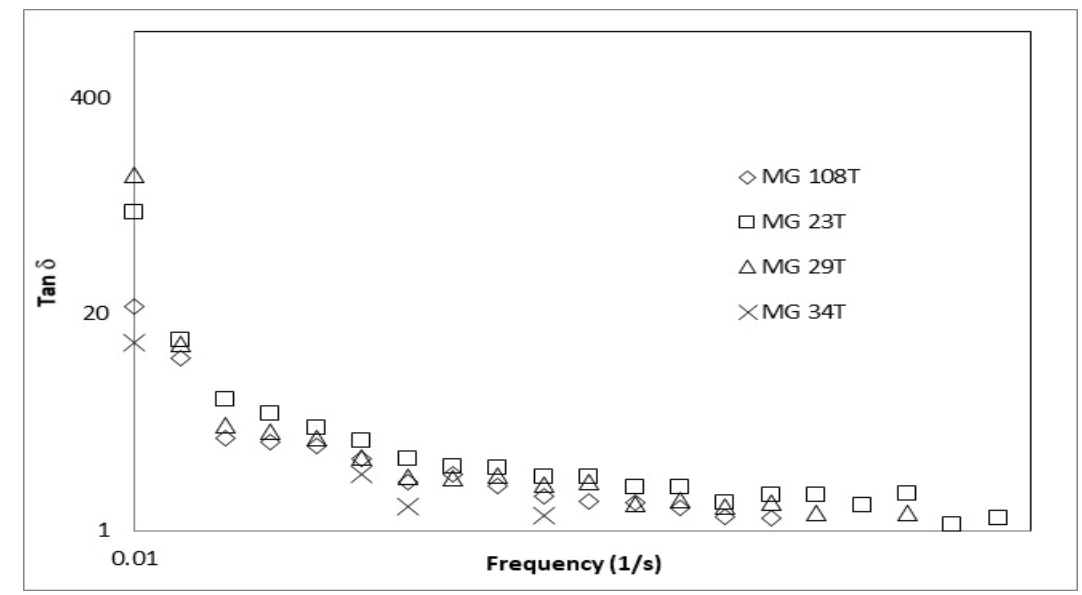

Figure 4: Tan $\delta$ versus frequency for different Kuwaiti crude oils at $298 \mathrm{~K}$.

Figure 4 is a plot of $\tan \delta$ versus frequency for different Kuwaiti crude oils at $298 \mathrm{~K}$. It is noted that the $\tan \delta$ values followed an ascending order as follows:

MG 34T (13.54) < MG 108T (22.41) < MG 23T (81.38) < MG 29T (137.1). From these observations, it is seen that crude oil MG 29T with a sulfur content of 1.977 and density of $0.895 \mathrm{~g} / \mathrm{cc}$ had the highest loss modulus value, while the lowest loss modulus value was found to be for the crude oil MG 34T with a sulfur content of 1.027 and density of $0.867 \mathrm{~g} / \mathrm{cc}$.

The models like Oswald De Ville and Bingham can describe the relation between viscosity and shear rate but cannot consider the effect of temperature and thus will be difficult to understand the physical nature of the processes occurring at molecular level. To understand the dependence of temperature on the rheological properties of the oil, the Arrhenius-Eyring equation given in equation (9) was employed.

$$
\eta=A_{i} \exp \left[\frac{n E a}{R T}\right]
$$

The activation energy value and the preexponential factor at a constant shear rate of $10.3 \mathrm{~s}^{-1}$ for the temperature range 298 to $313 \mathrm{~K}$ are shown in Table 3 . The $\mathrm{R}^{2}$ values of these plots shown in Figure 5 are greater than 0.94 .

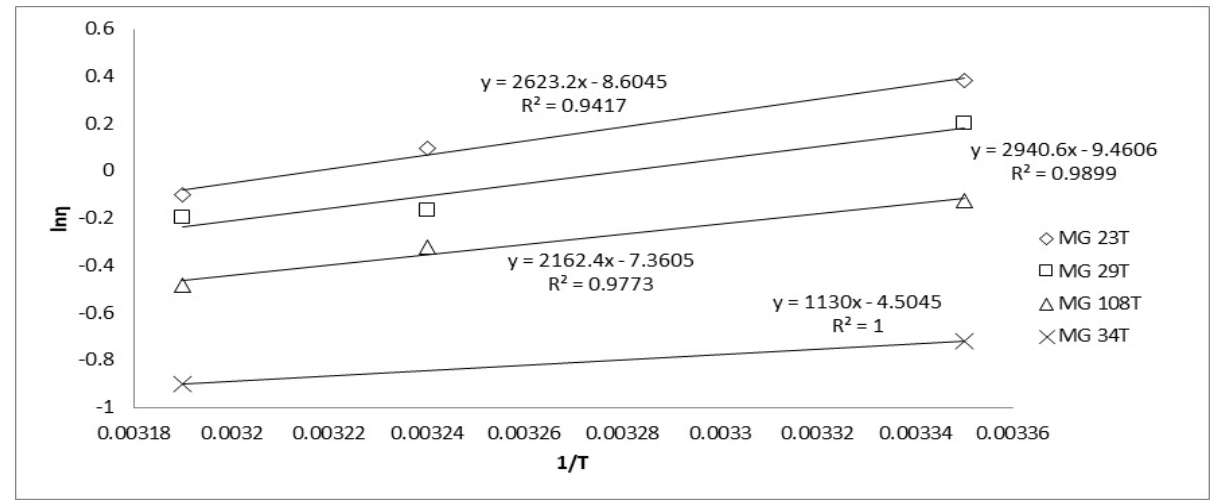

Figure 5. Plot indicating variation of in viscosity as a function of $1 / \mathrm{T}$. 
Table 3. Arrhenius -Eyring parameters for different Kuwaiti crude oils.

\begin{tabular}{|c|c|c|c|}
\hline & A (Pa.s) & Ea (J/mol.K) & $\mathbf{R}^{\mathbf{2}}$ \\
\hline 23T & 0.000184106 & 21809.80944 & 0.9417 \\
\hline 29T & $7.78599 \mathrm{E}-05$ & 24448.73652 & 0.9899 \\
\hline $\mathbf{1 0 8 T}$ & 0.00063588 & 17978.62608 & 0.9773 \\
\hline 34T & 0.00032506 & 18183.98682 & 0.9516 \\
\hline
\end{tabular}

\section{CONCLUSION}

Four Kuwaiti crude oil samples were collected, and their shear stress was evaluated as a function of the shear rate in the temperature range of $298-313 \mathrm{~K}$ in steps of $5 \mathrm{~K}$. The following conclusions were derived: The crude oil samples exhibit non-Newtonian (shear thinning) characteristics. The shear stress increases as the shear rate increases, and the temperature decreases. The non-Newtonian behavior is mostly observed at an elevated shear rate (above 80 $\mathrm{s}^{-1}$ ). This observation was confirmed by the flow index values obtained from the isothermal and nonisothermal models.

Crude oils MG 23T, MG 29T, and MG 108T can be modeled as a function of the shear rate and temperature by using the $\mathrm{O}$ model. In contrast, MG 34T can be modeled using the HB model.

The yield stress for samples MG 23T, MG 29T, and MG 108T is negligible, and based on the statistical parameters, the most representative model is the O model, while MG 34T has a certain yield stress, and this aspect is best represented by the HB model.

Based on the Arrhenius-Eyring equation, the activation energy values for the temperature range 25 to $40^{\circ} \mathrm{C}$ at shear rate of $10.3 \mathrm{~s}^{-1}$ varies in the range $17.9 \mathrm{~kJ} / \mathrm{mol} . \mathrm{K}$ to $2.4 \mathrm{~kJ} / \mathrm{mol} . \mathrm{K}$, and at the same shear rate, the preexponential value varied between $7.8 \times 10^{-5}$ and $0.63 \times 10^{-3}$ Pas.

\section{ACKNOWLEDGMENT}

The authors would like to thank the Research Administration of Kuwait University for providing funds from project RE 01/13. The authors would like to acknowledge Johnson Mathew, Joyson John, and Bader Masier for the technical support provided during this work. The authors would also like to acknowledge the PRP center GE 03/08 for analyzing the crude oil samples.

\section{REFERENCES}

Abramovi, Helena, and C. Klofutar. 1998. The temperature dependence of dynamic viscosity for some vegetable oils. Acta Chimica Slovenica 45 (1), pp. 69-77.

Albusairi, Bader H., \& Adam Al-Mulla. 2017. A Study of Flow Properties of Kuwaiti Crude Oil Obtained from Different Sources. Journal of Petroleum Science and Technology 7 (1). pp. 79-90. doi: 10.22078/jpst.2017.710.

Alomair, Osamah, Adel Elsharkawy, \& Hassan Alkandari. 2014. A viscosity prediction model for Kuwaiti heavy crude oils at elevated temperatures. Journal of Petroleum Science and Engineering 120, pp. 102-110. doi: https://doi.org/10.1016/j.petrol.2014.05.027.

Anawe, P. A. L., \& J. Adewale Folayan. 2018. Data analyses on temperature-dependent behaviour of water based drilling fluid rheological models. Data in Brief. 21, pp. 289-298. doi: https://doi.org/10.1016/j.dib.2018.09.100. 
Anto, Rincy, Sameerjit Deshmukh, Saheli Sanyal, \& Uttam K. Bhui. 2020. Nanoparticles as flow improver of petroleum crudes: Study on temperature-dependent steady-state and dynamic rheological behavior of crude oils. Fuel 275 (1), pp. 117873. doi: https://doi.org/10.1016/j.fuel.2020.117873.

Ariffin, Tajnor Suriya Taju, Effah Yahya, \& Hazlina Husin. 2016. The Rheology of Light Crude Oil and Water-In-Oil-Emulsion. Procedia Engineering 148, pp. 1149-1155. doi: https://doi.org/10.1016/j.proeng.2016.06.614.

Astarita, G., G. Marrucci, \& D. D. Joseph. 1975. Principles of Non-Newtonian Fluid Mechanics. Journal of Applied Mechanics 42 (3), pp. 750-750. doi: 10.1115/1.3423693.

Barnes, Howard A., J. F. Hutton, \& Kenneth Walters. 1989. An introduction to rheology. Amsterdam; New York: Elsevier : Distributors for the U.S. and Canada, Elsevier Science Pub. Co.

Bird, R.B., \& O. Hassager. 1987. Dynamics of Polymeric Liquids: Fluid mechanics: Wiley.

Cutlip, Michael B, \& Mordechai Shacham. 2008. Problem solving in chemical and biochemical engineering with POLYMATH, Excel, and MATLAB. 2 ed. Upper Saddle River, N.J.: Prentice Hall.

Darby, Ron. 1976. Viscoelastic fluids : an introduction to their properties and behavior. New York: M. Dekker.

Ding, Jianlin, Jinjun Zhang, Hongying Li, Fan Zhang, \& Xiaojing Yang. 2006. Flow Behavior of Daqing Waxy Crude Oil under Simulated Pipelining Conditions. Energy \& Fuels 20 (6), pp. 531-2536. doi: 10.1021/ef060153t.

Esteban, Bernat, Jordi-Roger Riba, Grau Baquero, Antoni Rius, \& Rita Puig. 2012. Temperature dependence of density and viscosity of vegetable oils. Biomass and Bioenergy 42 pp.164-171. doi: https://doi.org/10.1016/j.biombioe.2012.03.007.

Fakoya, Muili F., \& Ramadan M. Ahmed. 2018. A generalized model for apparent viscosity of oil-based muds. Journal of Petroleum Science and Engineering 165 pp. 777-785. doi: https://doi.org/10.1016/j.petrol.2018.03.029.

Kamel, Abdulrahim, Osamah Alomair, \& Adel Elsharkawy. 2019. Measurements and predictions of Middle Eastern heavy crude oil viscosity using compositional data. Journal of Petroleum Science and Engineering 173 pp. 990-1004. doi: https://doi.org/10.1016/j.petrol.2018.10.062.

Khalili-Garakani, Amirhossein, Navid Mostoufi, Fatemeh Sadeghi, M. Hosseinzadeh, Hooman Fatoorehchi, Mohammad Sarrafzadeh, \& Mohammad Mehrnia. 2011. "Comparison between different models for rheological characterization of activated sludge." Iranian Journal of Environmental Health Science \& Engineering 8 (3), pp. 255-264.

Mendes, Rafael, Guillaume Vinay, Guillaume Ovarlez, \& Philippe Coussot. 2015. Modeling the rheological behavior of waxy crude oils as a function of flow and temperature history. Journal of Rheology 59 (3):703732. doi: $10.1122 / 1.4916531$.

Middleman, S. 1977. Fundamentals of polymer processing: McGraw-Hill.

Ronningsen, Hans Petter. 1992. Rheological behaviour of gelled, waxy North Sea crude oils. Journal of Petroleum Science and Engineering 7 (3), pp. 177-213. doi: https://doi.org/10.1016/0920-4105(92)90019-W.

Ronningsen, Hans Petter. 1995. Correlations for predicting Viscosity of W/O-Emulsions based on North Sea Crude Oils. SPE International Symposium on Oilfield Chemistry, San Antonio, Texas, 1995/1/1/.

Ronningsen, Hans Petter. 2012. Rheology of Petroleum Fluids. Annual Transactions of the Nordic Rheology Society 20, pp. 11 - 18.

Stanciu, Ioana. 2013a. Exponential dependence of dynamic viscosity - shear rate for vegetable oils. Annals food science and technology 14 pp. 230-232.

Stanciu, Ioana. 2013b. New rheological models for vegetable oil. International Journal of Agriculture Innovations and Research 1 (4) pp. 107-108. 